\title{
ABORTO INDUCIDO
}

\author{
Benjamín Viel Vicuña
}





\section{ABORTO INDUCIDO*}

A diferencia de métodos anticonceptivos que previenen un embarazo no deseado, el aborto inducido es la terapéutica de un hecho ya producido que la mujer desea evitar que llegue a término. Deveraux ${ }^{1}$ señala que existió en épocas prehistóricas y probablemente es una de las más antiguas maniobras médicas. Según este autor, hubo sociedades primitivas que recurrieron a él empleando hierbas a las cuales atribuían efectos favorables para inducir menstruaciones atrasadas que denunciaban un embarazo en evolución. Otras sociedades recurrían a masajes. Por último, las tribus que practicaban el canibalismo, por lo tanto conocían mejor la anatomía humana, recurrían a maniobras quirúrgicas. En sociedades industriales se ha usado ampliamente recurriendo a la cirugía, lo cual, antes de conocerse la antisepsia, debe haber provocado numerosas muertes por infección.

Dorothy George $e^{2}$ después de estudiar cómo era la vida londinense a principios de la Revolución Industrial, publicó un interesante libro (desgraciadamente no traducido al español) donde habla sobre una epidemia que mató a muchos recién nacidos en las clases proletarias. La medicina de la época la denominó convultions: el niño sufría convulsiones hasta morir asfixiado. Su frecuencia llamó la atención de médicos británicos, que, después de investigar, concluyeron que era una forma de infanticidio. La embarazada, en condiciones de miseria extrema, incapaz de pagar una abortera empírica o temiendo morir por una infección, optaba por llegar hasta el parto y dar al recién nacido una cucharadita de ginebra, lo que provocaba un espasmo laríngeo que impedía el ingreso de aire a los pulmones, sin dejar muestras externas de violencia. La época de estos trágicos sucesos coincidió con la introducción de la ginebra como bebida alcohólica, que al principio resulto extremadamente toxica por las impurezas que contenía. La ley británica prohibió su expendio desde los toneles directamente a los vasos, exigiendo que se vendiera en botellas elaboradas por firmas responsables que eliminaran las impurezas tóxicas; desde entonces el gin es una bebida alcohólica de uso corriente en todo el mundo. Este trágico ejemplo se cita como demostración de que el aborto inducido es un avance sobre el infanticidio, que aun se observa en recién nacidos abandonados en parques o sitios ocultos.

El peligro de la infección y la muerte de los abortos inducidos, en los cuales la medicina se rehusaba a participar, obligaban a las mujeres a recurrir al "torno", de los conventos católicos de claustro que existían siglos atrás. En los cementerios de dichos conventos, se han encontrado esqueletos de niños de corta edad. Embarazadas que

* Texto íntegro de Viel, B., "Aborto Inducido", en su La vida en la tierra y el ascenso del hombre; Demografía y el derecho de la mujer, Santiago de Chile: Editorial Cuatro Vientos, 1996, págs. 65-48

1. Deveraux, G.A., A Typological Study of Abortion in 350 Primitive, Ancient and Pre-Industrial Societies, Nueva York: Ed. Harold Rosen, 1954.

2. Ibíd., London Life in the Eighteen Century, New York: Capricorn Books, 1965. 
deseaban ocultar su estado viajaban o se escondían en sus casas; al nacer el niño, lo depositaban en el torno para que las monjas cuidaran de esa criatura que la madre rechazaba o se veía obligada a hacerlo. En las clases pobres de América Latina no es del todo extraño el fenómeno del "niño dado" a otra mujer que lo acepta y cría como propio. En clases de mayor cultura, este fenómeno se reemplazó por leyes de adopción, a veces tan restrictivas y con trámites legales tan caros, que, por el bienestar del niño, deberían ser revisadas y facilitadas.

En su continuo avance desde el empirismo hasta el método científico, la medicina aprendió que había enfermedades incompatibles con el embarazo. Aun recuerdo las clases de obstetricia con el Dr. Carlos Monckeberg, quien citaba la frase de un profesor francés que, frente a mujeres con estenosis de sus válvulas cardiacas, decía: "La soltera que no se case, la casada que no se embarace y la embarazada que no llegue a termino su embarazo"- El reconocimiento de estas condiciones, tema propio de los tratados de obstetricia, originó el concepto de "aborto terapéutico", técnica aceptada por la medicina y las leyes de prácticamente todos los países del mundo, pero no por la religión católica.

Las obstrucciones en la trompas - como consecuencia de procesos inflamatorios parciales que dejan lumen suficiente para el paso de espermatozoides- suelen producir embarazos tubarios en que el embrión se desarrolla en la trompa sin poder llegar al útero. Si se hace un diagnostico precoz, la mujer debe someterse a una intervención quirúrgica para extirpar la trompa afectada. Pero en la mayoría de los casos, el diagnostico es tardío y la trompa se rompe provocando una hemorragia que, si no se opera a tiempo, produce la muerte de la madre. En la intervención de urgencia se asume que el embrión ha muerto, lo que no ocurre si el diagnostico es precoz, aunque la operación que salva la vida de la mujer produce la muerte del embrión.

En el siglo XIX, las leyes de casi todos los países prohibían el aborto inducido, condenando a prisión a quien se sometiera a él y a quien lo practicara. Tales disposiciones no impedían que esta práctica creciera y así aumentara la mortalidad materna.

En 1920, la Rusia soviética fue el primer país que legalizó el aborto inducido, siempre que se practicara en el curso de las doce primeras semanas de embarazo. Dos razones impulsaron al gobierno ruso: el derecho de la mujer a la propiedad de su cuerpo, y la gran mortalidad materna a causa de los abortos ilegales efectuados por manos inexpertas. Por cierto, este cambio legal provocó asombro y fuerte oposición del resto del mundo. Solo dos o tres países del norte de Europa favorecieron el cambio. A mediados de la década del 30, Stalin revocó la ley y el aborto volvió a ser ilegal. En esa época, todo parecía indicar que la inminencia de una segunda guerra mundial. Al visualizarla, Stalin cambio la ley a fin de aumentar los nacimientos para reemplazar a los que morirían en el conflicto que finalmente estalló en 1939, cuando Alemania invadió a Polonia. Al término de la guerra, en 1945, habían muerto cerca de 30 millones de rusos, a los que habría que agregar los muertos de las potencias aliadas de Occidente, del eje Berlín-Roma y de Japón.

Después de esta guerra -probablemente la más cruenta de la historia-, el mundo europeo inició paulatinamente su reconstrucción. Gran parte de las viviendas y fábricas estaban destruidas. Las condiciones de vida eran muy precarias y gradualmente el aborto inducido fue legalizado, primero en el mundo occidental y luego en otros continentes. A 
esta tendencia contribuyeron dos factores de suma importancia: los movimientos feministas que iniciaron su lucha por los derechos a la maternidad voluntaria, y el progreso medico en las técnicas empleadas para practicar el aborto.

Recuerdo haber visto fotografías de mujeres desfilando en Roma con lienzos que decían: "No somos santas ni prostitutas, somos mujeres". Ganaron y el aborto se legalizó durante cinco años, al final de los cuales se repitió la votación, ganando por una mayoría más alta que la primera vez. Los médicos cuyas ideas religiosas les impedían practicarlo, tenían derecho a negarse, pero debían informar donde recurrir. En Europa circularon cartas firmadas por intelectuales y artistas que confesaban haberse practicado abortos. En Francia, el plebiscito similar al italiano ganó por mayoría. El parlamento ingles también lo aprobó, y la Iglesia Anglicana declaró que ante el dilema entre el embrión o la vida y salud de la madre, debía preferirse esta última. También lo aprobaron en Dinamarca, Holanda, Suecia, Noruega y Finlandia, y los países que al término de la guerra quedaron bajo la influencia de la Rusia soviética. De estos, la excepción fue Rumania, cuyo dictador Ceausescu lo prohibió junto con la distribución de métodos anticonceptivos. Entonces, no solo aumentó la natalidad, sino también la mortalidad matera. Terminada la dictadora, se volvió a legalizar. En Polonia, el parlamento aprobó una ley que legalizaba el aborto inducido, pero el presidente la vetó y no se lograron los dos tercios parlamentarios para anular el veto, pero la baja Tasa Cruda de Natalidad permite sospechar una frecuencia de abortos ilegales.

La técnica quirúrgica el aborto exigía anestesia y dilatación progresiva del cuello uterino. Cuando se lograba esto, se introducía un instrumento en forma de cucharillas que raspaba el endometrio limpiando la cavidad uterina. Solo el tacto del operador impedía que tal raspado fuera excesivo, dejando a la mujer estéril. Terminaba la maniobra, que producía abundante sangrado, debía permanecer en reposo hasta su recuperación. El uso de instrumental estéril y la habilidad y experiencia del operador evitaban las complicaciones posteriores. Aborteras empíricas, y en ocasiones la propia embarazada, introducían una sonda a través del cuello uterino, rompiendo el huevo. Al producirse la hemorragia, recurrían al hospital para el tratamiento de limpieza de restos del interior del útero. El uso de instrumental no debidamente esterilizado inducía una infección que, en la época previa a los antibióticos, generaba numerosas muertes por aborto séptico. No era infrecuente que al introducir la sonda, que no siempre era flexible, se perforara la pared uterina, agregando mayor riesgo. Se discute si fue Japón o China donde primero de usó el aborto por succión para la limpieza de la cavidad uterina. Hoy, una maquina de vacío conectada al cuello del útero permite el vaciamiento de la cavidad, simplificando la riesgosa maniobra de raspado de endometrio. Como este instrumento deber ser empleado por profesionales, su uso no ha eliminado del todo la vieja maniobra de raspado previa dilatación del cuello, ni el uso de sondas introducidas para romper el huevo. La succión, que hoy se emplea en al mayoría de los países, produce menos sangrado, y el estricto cuidado de la antisepsia previene la posibilidad de infección.

En los últimos años, se descubrió un método abortivo no quirúrgico: el RU 486 combinado con prostaglandina. Si se usa en los primeros 50 días de embarazo, induce un aborto en más del 97\% de los casos. Este método se aprobó en Francia y en China, 
se encuentra pendiente en Estados Unidos. Mientras mayor la edad gestacional, mayor el porcentaje de fracasos y mayor necesidad de complementarlo con cirugía. Se exige que este método sea practicado en hospitales autorizados.

En una época se uso la regulación menstrual que no exigía el diagnostico previo de embarazo y se realizaba con un sencillo instrumento capaz de producir succión. Se empleaba en mujeres con un atraso menstrual. Guardando las debidas precauciones de antisepsia, incluso un no profesional con un simple entrenamiento podía efectuarlo sin mayor riesgo. Examinando restos de la menstruación obtenida, se confirmó un alto porcentaje de casos en que no había habido embarazo y la maniobra habría sido un riesgo inútil. Este método se sigue empleando sin ser promovido por la medicina.

Las leyes vigentes permiten el aborto a pedido de la embarazada en un porcentaje estimado de $40 \%$ de la población mundial. En la mayoría de los países, la edad gestacional autorizada para el aborto sin más requisito que el deseo de la embarazada es de doce semanas. Pasado este plazo, solos por razones médicas, cuando la continuación del embarazo pudiera afectar la salud de la mujer. Este requisito de edad tiene su justificación: mientras más temprano se induzca el aborto, es más fácil practicar y está sujeto a menos riesgos. Los abortos precoces requieren solo algunas horas de reposo después de la intervención, mientas que los tardíos exigen hospitalización.

Según una publicación ${ }^{3}$ distribuida por la Population Action International en 1993, el aborto a pedido de la embarazada, y sin más justificación que su voluntad, es legal; el 40\% de las mujeres del mundo están favorecidas por tal legislación. A este alto porcentaje habría que agregar un $21 \%$ en que el aborto es legal cuando existen razones médicas o socioeconómicas que lo justifiquen, y un 16\% más en que hay razones para estimar que la continuación del embarazo constituye un riesgo para la salud de la mujer, o bien, el embarazo ha sido consecuencia de violación o incesto. Por lo tanto existe un $77 \%$ de mujeres con derecho al aborto legal. En el 23\% restante es legal solo para salvar la vida de la madre, y dentro de este grupo, un porcentaje muy pequeño lo considera ilegal en toda circunstancia.

Esta publicación se refiere al porcentaje de mujeres que tienen acceso al aborto legal precoz, vale decir, dentro de los primeros tres meses de edad gestacional. Todas las legislaciones existentes establecen que, pasado ese plazo, el aborto solo debe autorizarse por razones médicas.

El alto porcentaje de mujeres beneficiadas con la legalización del aborto no se refiere a los países que se ha legalizado. Siendo un proceso de cambio durante la segunda mitad del presente siglo, se podría estimar que en 1993 el aborto ya ha sido legalizado en más de 40 países y que en otros 50 se permite por una serie de indicaciones médicas y/o socioeconómicas. Hoy en día, en todo el mundo existen grupos que luchan por facilitar el acceso al aborto legal, así como grupos que se oponen sosteniendo que es un crimen que destruye la vida humana. Para los partidarios del aborto, el embrión que se está gestando en el útero es un proyecto de vida que difícilmente podría considerarse un ser humano vivo. La discusión sobre cuando comienza la vida de un ser ya tiene siglos de controversia. En el pasado, la religión cristiana consideraba que la vida comenzaba al

3. Lista de países donde se ha legalizado el aborto. 
iniciarse los movimientos fetales. Nuevos conocimientos biológicos han llevado a muchos teólogos a considerar que la vida se inicia con la fecundación del ovulo, concepto bastante dudoso, pues el ovulo fecundado carece de individualidad y puede dividirse en dos durante su viaje por la trompa, originándose un embarazo de gemelos univitelinos. Sin duda la controversia continuara largo tiempo. Para quien escribe estas líneas, así como para los legisladores que han aprobado leyes de aborto, el embrión es un proyecto de vida humana que al llegar a ser viable, vale decir, capaz de vivir fuera del útero materno, es un ser humano nacido vivo.

Muchas legislaciones han legalizado el aborto al confirmarse defectos congénitos por alteraciones cromosómicas. En la mayoría de los casos, tales diagnósticos son tardíos y el aborto debe hacerse solo si la madre lo acepta una vez informada. Enfermedades virales de la madre podrían afectar al embrión provocándole deformaciones congénitas, en cuyos casos se justifica el aborto para impedir el nacimiento de un niño anormal que va a significar una carga familiar y social. Es especialmente grave el caso de madres enfermas o portadoras del virus del SIDA, que tendrán un porcentaje de niños infestados que morirán durante sus dos primeros años de vida. En estos casos, el aborto sería ampliamente justificado.

Donde el aborto no es legal o lo es con regulaciones muy restringidas, existe en gran magnitud el aborto ilegal, peligroso y dañino para la salud de la mujer, pero prácticamente sin riesgo para las mujeres que pueden pagar profesionales competentes. Mientras mayores la penas para quienes practican abortos, mayor el riesgo que ellos afronten y mayor el costo para quienes lo solicitan. Se puede concluir que las legislaciones que prohíben el aborto solo lo encarecen y actúan contra los pobres. Esto me lleva a pensar que, en el Ministerio de Salud de Cuba, la reglamentación del aborto es la más cercana a combatir los graves peligros del aborto ilegal. En Cuba, la mujer tiene derecho al aborto dentro de las primeras diez semanas de embarazo; pasado ese plazo, solo por indicaciones médicas para protegerla salud. Se castiga con prisión a quien lo provoca contra la voluntad de la embarazada, a quien no está debidamente entrenado, a quien lo practica sin el material y equipo apropiado y a quien cobra por efectuarlo. Con esta reglamentación, única en América Latina, destinada a proteger la salud de la mujer y el niño, Cuba muestra hoy la tasa de natalidad y de mortalidad materna e infantil más baja del continente, comparable a la de Europa Occidental.

Se estima que en América Latina los abortos legales anuales sobrepasan los 3 millones de casos, y hay quien piensa que superan los 4 millones.

En Chile, el aborto, que siempre ha sido ilegal, se penalizaba con dos años de prisión a quien se sometiera a él y a quien lo practicara. En 1989, en uno de los últimos decretos leyes promulgados por el gobierno militar, se modifico el Código Penal prohibiendo toda forma de aborto, aun aquella por indicaciones médicas para proteger la salud de la madre, e igualándola con homicidio simple, que debe castigarse con más años de prisión. Previo a este decreto, como los miembros de la Junta Militar -que fueron el poder legislativo durante diecisiete años de dictadura- no eran expertos en medicina, consultaron a profesores universitarios que se pronunciaron uniformemente en contra, salvo los de la Escuela de Negocios de Valparaíso, quienes fueron finalmente los únicos 
escuchados. Al promulgar el decreto (aun no modificado por el Parlamento), no repararon en que el castigo impuesto es incumplible como en el Código Penal previo, pues las cárceles de mujeres están llenas de delincuentes comunes, y si se condenara a una mujer que ya tiene hijos, no hay sitios donde albergar a esos niños. Hasta ahora nada indica que este irracional decreto haya disminuido el aborto ilegal, que sigue estimándose entre 150 y 200 mil anuales. ¿Tendrán los tribunales capacidad para juzgar este número de casos? ¿Estarán dispuestos los médicos a denunciar a la policía a mujeres que legan a los hospitales con graves complicaciones de un aborto infestado? ¿No está la ética médica obligada a guardar el secreto profesional del diagnostico de la enfermedad no es contagiosa?

El mencionado decreto ineludiblemente aumentará la cifra de muertes maternas, especialmente embarazadas con dolencias cardiacas o renales, aun cuando estén en tratamiento. El embarazo, y el esfuerzo del parto necesariamente acortaran sus vidas, se es que no mueren durante el embarazo. Cabe recordar que ninguna de estas enfermedades es curable: medicamentos, dietas y régimen de vida no pueden sanarlas, aunque ciertamente prolongan la vida.

En relación a efectos dañinos en la salud de la mujer, debe agregarse que, mientras este decreto esté vigente, es comprensible que la medicina chilena esté impedida de introducir progresos tales como la succión par la limpieza de la cavidad uterina. Ni hospitales públicos ni clínicas privadas se interesaran en adquirir maquinas de succión o capacitar personal para manejarlas. Al no existir estas maquinas, un aborto espontáneo en que han quedado restos dentro de la cavidad uterina tendré que ser limpiado con el anticuado método de la cucharilla que raspa el endometrio. Menos probable aun es la introducción del método no quirúrgico RU 486.

La historia del aborto ilegal en Chile no es distinta a la de otros países de América Latina. La única diferencia es que Chile fue pionero en el uso de métodos anticonceptivos voluntarios y gratuitos que lograron descender las altas tasas crudas de natalidad de 36 por mil en 1965 a 22 por mil en 1980. Desde esta fecha, la tasa se ha mantenido estable gracias a la política de salud del régimen militar iniciado en 1973. Al principio, el gobierno dictatorial dio indicaciones para que no se modificara el programa de planificación familiar puesto en marcha en 1965, pero lentamente se fueron introduciendo medidas que disminuyeron su eficacia. Para reducir la inflación monetaria con la disminución del gasto público, se redujo el número de médicos y matronas en los consultorios: debía darse preferencia a la mujer que consultaba por enfermedad, luego a quien concurría por el control de embarazo y finalmente a quien solicitara métodos anticonceptivos. Muchas mujeres que deseaban obtenerlos no alcanzaban a ser atendidas, cifra que nunca figuré en las estadísticas de atenciones efectuadas, pues se las consideraba como citadas para la fecha posterior. Mujeres de sectores pobres gastaban dinero en transporte hasta los consultorios, y si eran postergadas una o dos veces, perdían la esperanza de ser atendidas, debiendo afrontar un embarazo no deseado.

Previo a 1965, no fue fácil que se reconociera el derecho de la mujer a regular su fertilidad y tener una maternidad voluntaria. La Iglesia Católica, mayoritaria en el país, siempre se opuso al aborto y a los métodos anticonceptivos, con excepción de la abstinencia periódica. A su oposición, se agregaron grupos de izquierda influenciados por 
la política de Mao en China y de Fidel Castro en Cuba. Sin duda, el movimiento por uso de métodos anticonceptivos se detuvo no por culpa de las mujeres que siempre lo solicitaban, sino por los gobiernos que, temiendo la oposición de la Iglesia Católica y de grupos de izquierda, no implementaron a tiempo medidas para satisfacer la demanda de las mujeres.

A la valiente actitud del profesor Gacitúa en 1937, siguió una etapa de silencia que sólo se rompió cuando el número de abortos sépticos, e su mayoría inducidos ilegalmente, sobrepasó la capacidad e los hospitales para atenderlos; entonces se cerraron salas de obstetricia para abrir sala de aborto séptico. Las parturientas eran dadas de alta hospitalaria con solo un día de reposo, debiendo volver al hogar a atender a sus otros hijos y al marido, lo cual sin duda aumentaba la mortalidad neonatal y materna.

Tanto el gobierno como APROFA declaraban que el aborto inducido estaba fuera de los servicios ofrecidos, y aunque tendió a disminuir, siguió siendo frecuente. El Código Penal imponía dos años de prisión a quien se sometiera a un aborto y a quien lo provocara. Los pocos juicios por tales delitos se debieron a que la mujer había muerto en la maniobra. Aparentemente, los médicos se negaban a denunciar a mujeres víctimas de aborto séptico que recurrían a ellos para salvar sus vidas. Además, estaban protegidos por el Código Civil, que los obligaba a guardar el secreto profesional del diagnostico en enfermedades no contagiosas.

La prevención siempre es preferible al tratamiento de un hecho ya producido. El aborto no es la excepción a esta regla médica, especialmente en una época en que existen métodos, aunque no cien por ciento eficaces, para prevenir el embarazo. Las mujeres en riego deben conocer los métodos anticonceptivos y su uso correcto, lo que obliga al hombre a reconocer su responsabilidad y proteger a la mujer de un embarazo que no desean. Este concepto lleva a impartir en el sistema escolar una educación sexual y reproductiva hoy defectuosa, incompleta y en muchas ocasiones inexistente. Tal educación, que debiera iniciarse antes del despertar sexual de los jóvenes, debe ser la primera barrera contra el embarazo no deseado. En Chile, la educación sexual se dificulta al no existir una debida preparación del profesorado y por el traspaso de la educación a las municipalidades, dejando al ministerio sin autoridad suficiente al respecto.

En un país como el nuestro, en nada diferente al resto del continente latinoamericano, el costo de los servicios anticonceptivos constituye una barrea para su uso. Si es justo que mujeres o parejas de buena situación económica cancelen los servicios prestados, también es cierto que prefieren recurrir a la medicina privada antes que a la pública. En países con salarios bajos, desempleo y grupos marginales de extrema pobreza, las tarifas de los servicios anticonceptivos limitan severamente el porcentaje de usuarias. Sería preferible una política de servicios gratuitos en que se solicite a los usuarios que, si se sienten bien atendidos, paguen lo que puedan para mantener la calidad de dichos servicios.

El aborto inducido ${ }^{4}$ que en el mundo de hoy tiende a ser despenalizado, debería ser legal cuando existan enfermedades previas al embarazo o causadas por éste, cuando el

4. Requena, M. et al., "El aborto inducido en Chile", Sociedad Chilena de Salubridad, 1990, en Tietze, C., Henshaw, S.K., Induced Abortion. A World Review. A Population Fact, Nueva York, 1981. 
embarazo sea producto de violación o incesto, cuando se confirme previamente que el producto de la concepción tiene defectos genéticos incompatibles con una vida normal, cuando la situación económica de la mujer o pareja no garantice el debido cuidado del niño, o cuando la embarazada sea portadora del virus del SIDA (el porcentaje de nacidos afectados justifica de sobra esta actitud).

Los países que han legalizado el aborto a pedido de a embarazada dentro de los tres primeros meses, justifican su actitud al proporcionar una autentica maternidad voluntaria. Además, sostienen que las comisiones ante las cuales la muerte debe explicar los motivos para solicitar el aborto tienden a demorar el procedimiento, con el peligro de que se sobrepase el plazo de tres meses de embarazo. En cambio, si la solicitud se aceptara sin mayor trámite, se garantizaría el nacimiento de hijos realmente deseados por sus madres. Pero tiene el inconveniente de desalentar el uso de métodos preventivos: las mujeres podrían preferir el aborto precoz en lugar de las molestias del uso prolongado de métodos. Esto podría corregirse con una educación continua durante la vida fértil que señale el riesgo de abortos repetidos.

Una mujer que ha sufrido un aborto, espontáneo o inducido, está convaleciente de una traumática experiencia físico-psicológica y carece de protección del periodo anovulatorio que sigue por algunos meses al parto normal. El aborto no es preventivo, la mujer sigue siendo fértil y en riego de un nuevo embarazo que debe ser evitado hasta su completa recuperación, con un método anticonceptivo eficaz. Si es aborto es espontáneo, ella estará anémica por la hemorragia y no debe embarazarse hasta su completa recuperación. Si el aborto fue inducido, la metódica anticonceptiva aconsejada debe mantenerse hasta que exista un deseo real de embarazo.

La nueva ley en Chile, que lleva cuatro años en vigor y fue publicada por decreto prohibiendo hasta e aborto terapéutico, merece una pronta revisión que se base principalmente en el derecho del niño a nacer deseado no como el simple producto de un instinto que la abstinencia fue incapaz de controlar ${ }^{5}$.

Muchos piensan que no se justifica una ley para autorizar el aborto, aun cuando reconocer que se debe modificar este decreto que lo iguala al homicidio simple. Sostienen que el problema está solucionado gracias al uso de métodos anticonceptivos, Pero olvidan las dificultades para obtenerlos: las largas filas de mujeres que esperan en los consultorios desde muy temprano y muchas en horarios incompatibles con su trabajo, hacen que un alto porcentaje no alcance a ser atendido. Es un craso error sostener que Chile tiene un adecuado crecimiento demográfico -su natalidad solo es inferior a otros países del continente menos desarrollados. Nuestra natalidad es aun más del doble de aquella de Europa Occidental, y nuestro país sigue creciendo un 1,6\% anual comparado con el 0,2\% de Europa Occidental.

También olvidan que los mejores métodos anticonceptivos tienen u porcentaje de fracaso que, acumulado en el tiempo, llega a ser lo suficientemente alto como para originar un gran número de hijos no deseados que no siempre lograran conquistar el cariño al cual tienen derecho. En nuestros sectores políticos no existe gente contraria a

5. Valdés, T., Bustos, M., Sexualidad y reproducción, Santiago de Chile: CORSAPS/FLACSO, 1994. 
la igualdad de derechos de la mujer, igualdad defendida por declaraciones explicitas de Naciones Unidas y por grupos feministas. Sin embargo, se sigue negando a la mujer la propiedad de su cuerpo, y al negarle el derecho al aborto aun por razones medicas, se le está negando a proteger su salud.

Cuando los países hispanoamericanos se independizaron en los primeros años del siglo pasado, tendieron a basar sus legislaciones en el Código Napoleónico. Francia fue el modelo de nuestros primeros ordenamientos jurídicos. Ya que Napoleón era soldado y por cierto creía en el uso de la fuerza, aspiró a la unión europea por la fuerza de las armas. Su código consideraba a la soltera como débil mental y a la casada como propiedad del marido. A fines del siglo XIX, Francia inició la modificación de sus códigos. En 1880 otorgó acceso igualitario a la Educación Secundaria y en 1884 a la Educación Universitaria. Durante el presente siglo, el Parlamento francés aceptó modificaciones tendientes a otorgar derechos igualitarios a las mujeres, como lo muestran las fechas y modificaciones introducidas a lo largo del siglo:

1907 Mujeres casa que percibían salarios, obtienen el derecho de manejarlos independientemente de sus maridos.

1938 Las mujeres dejan de ser c consideradas menos de edad ante la ley

1945 Obtienen el derecho a voto y a ser miembros del Parlamento y del Poder Ejecutivo y Judicial; así como derechos igualitarios en todos los dominios.

1963 Obtienen el derecho a manejar cuentas bancarias sin la autorización del marido.

1968 Se legaliza el uso de métodos anticonceptivos

1972 Obtienen el derecho de percibir una remuneración igualitaria a la del hombre ante igual responsabilidad en el trabajo

1975 Obtienen el derecho al término voluntario del embarazo antes de las diez semana de gestación; después, sólo por causas médicas.

1977 Se libera del trabajo a los padres por un corto periodo después del nacimiento o adopción de un hijo

1978 Madres que recién han tenido u hijo, obtienen garantías de horario flexible y tiempo parcial.

Hasta 1968 se puede observar gran similitud con modificaciones a la legislación chilena, donde algunas veces nuestros cambios precedieron a los franceses. A diferencia de Francia, en Chile no se ha aprobado la terminación del embarazo, lejos de ello: se han aumentado las penas y prohibido el aborto terapéutico. Tampoco el marido ha obtenido facilidades para ayudar y acompañar a la parturienta.

En la reunión efectuada en Oaxaca, México, cuyo tema fue "Sexualidad en la Adolescencia", el Presidente del Population Council, Dr. Zeidenstein ${ }^{6}$, presentó un brillante análisis de las modificaciones sufridas por el Código Napoleónico que rigiera Francia hasta fines del siglo XIX. El autor sostuvo que si las legislaciones del mundo rigieran cambios similares, la explosión demográfica tendería a disminuir.

6. Dr. Zeidenstein, trabajo sobre sexualidad y adolescencia, Oaxaca, México, 1973. 


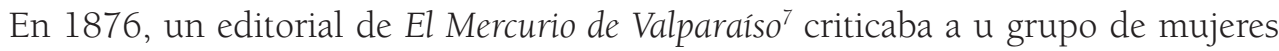
que habían concurrido a las galerías del Congreso a escuchar un debate parlamentario. El articulo decía textualmente: "Guarden de pisar esos centros que podrían destruir sus ideales de mujer, de esposas y hasta de madres". Hoy existen mujeres parlamentarias, pero aun se les niega el derecho a una maternidad voluntaria.

El acceso igualitario a la educación abrió a la mujer el mercado del trabajo, ciertamente incompatible con una fecundidad irrestricta, con lo cual dejamos atrás esa época victoriana en que se inventaban sentimientos feminismo asumiendo que en ellas no había deseo sexual y que debían permanecer vírgenes hasta el matrimonio, de lo contrario, perdían el "honor". No se puede seguir aceptando que haya dos clases de mujeres: una para el placer y otras para el amor puro. Por ello suscribimos plenamente la frase del sociólogo uruguayo Arnaldo Gomensoro: "No puede considerarse justa una sociedad donde lo que para el hombre es un galardón para la mujer es un baldón".

En 1994, The Alan Guttmacher Institute ${ }^{9}$ publicó un completo análisis de la situación del aborto clandestino en Brasil, Colombia, México, Perú, República Dominicana y Chile, seis países latinoamericanos que suman cerca de la mitad de la población del continente. Este serio y bien documentado análisis permite concluir que penalizar el aborto con prisión, como lo establecen los países de este continente (excepto Cuba), no reduce el número de abortos ilegales anuales que los anticonceptivos en uso no consiguen detener, aun cuando logre disminuirlo. La represión provoca mayor angustia en la embarazada que no desea que su embarazo llegue a término, mayor número de complicaciones, y aun de muertes, y mayor costo de la atención medica.

Este estudio debería ser cuidadosamente analizado por los legisladores del continente, ya que verían la injusticia actual de América Latina, donde impera un régimen común de bajos salarios y una ignorancia generalizada sobre educación sexual. Chile, al homologar el aborto al homicidio simple aumentando los años de prisión, cometió un error que pronto debería ser reparado. Un homicidio es un crimen en todas partes del mundo; un aborto es la interrupción de un proyecto de vida que no puede ser equivalente a un homicidio.

Por el bienestar de mujeres y niños, esperamos que una pronta legislación modifique las actuales disposiciones que impiden el verdadero ejercicio de la maternidad consciente, reemplazando a la actual maternidad instintiva.

7. El Mercurio de Valparaíso, citado en la Historia del Liceo Femenino de Copiapó con motivo de su primer aniversario.

8. A. Gomensoro, trabajo presentado en la Reunión Anual del Consejo Regional de la Western Hemisphere Region (1989).

9. The Alan Guttmacher Institute, Aborto clandestino, una realidad latinoamericana, Nueva York; Washington: AGI, 1994. 